\title{
Quantificação de matéria orgânica do solo através de modelos matemáticos utilizando colorimetria no sistema Munsell de cores
}

\author{
José A. M. Demattê ( $\left.{ }^{1 *}\right)$; Marco Antonio Melo Bortoletto (1); Gustavo M. Vasques ( $\left.{ }^{2}\right)$; Rodnei Rizzo (1) \\ (') Universidade de São Paulo, Escola Superior de Agricultura “Luiz de Queiroz”, Departamento de Ciência do Solo, Caixa Postal 9, \\ 13418-900 Piracicaba (SP). \\ (2) Universidade Federal Rural do Rio de Janeiro, Departamento de Solos, BR 465, Km 7, 23890-000 Seropédica (RJ). \\ (*) Autor correspondente: jamdemat@esalq.usp.br
}

Recebido: 19/mai./2010; Aceito: 9/set./2010

\section{Resumo}

O presente estudo teve como objetivo desenvolver modelos matemáticos para a quantificação do teor de matéria orgânica, a partir da cor do solo, obtida por aparelho colorímetro no sistema Munsell de cores. Para esse fim, 912 amostras de solo foram coletadas na região de Porto Grande (Amapá) e enviadas para análises química, granulométrica e determinação da cor em amostras secas e úmidas. Os componentes valor e croma da cor do solo no sistema Munsell, obtidos por colorímetro, foram utilizados para quantificar através de regressão múltipla passo a passo (stepwise) o teor de matéria orgânica do solo. O modelo de predição com base em todas as amostras apresentou $R^{2}$ de 0,66 para amostras úmidas e 0,56 para amostras secas, ao serem validados utilizando amostras independentes. Foi possível ainda melhorar os modelos quando as amostras foram separadas por classe de solo ou textura, e os modelos gerados com base em cores de amostras úmidas foram sistematicamente superiores àqueles utilizando amostras secas. Em relação às classes de solo, os melhores resultados foram obtidos para Argissolos e Latossolos, ambos gerando um $\mathrm{R}^{2}$ de validação independente de 0,73 (amostra úmida). Para textura, os melhores resultados foram obtidos para solos de textura muito argilosa, com $R^{2}$ de validação de 0,81 (amostra úmida). Os modelos de predição de matéria orgânica em função da cor do solo possuem simplicidade e potencial para serem utilizados no laboratório e no campo, especialmente para Argissolos e Latossolos de textura argilosa, de maneira automática e sem necessidade de uso de produtos ou reagentes.

Palavras-chave: textura, classe de solo, cor do solo, colorímetro.

\section{Quantification of soil organic matter using mathematical models based on colorimetry in the Munsell color system}

\begin{abstract}
This study aimed to derive mathematical models to predict the soil organic matter content based on soil color obtained by a colorimeter in the Munsell color system. A total of 907 soil samples were collected in the region of Porto Grande (Amapá, Brazil) and analyzed in the laboratory for chemical properties, particle size distribution and color of dry and wet samples. The Munsell color components value and croma obtained using a colorimeter were used to predict soil organic matter content based on stepwise multiple linear regression. Models derived using all samples had $\mathrm{R}^{2}$ of 0.66 for wet samples and 0.56 for dry samples, respectively, when validated using independent samples. It was possible to improve the models by separating the samples by soil class or texture. The models derived using colors obtained from wet samples were systematically better than those based on dry samples. Among soil classes, best results were obtained for Argissolos (Ultisols) and Latossolos (Oxisols), both having an $\mathrm{R}^{2}$ of independent validation of 0.73 (wet sample). For texture, best results were obtained for very clayey soils, with an $\mathrm{R}^{2}$ of validation of 0.81 (wet sample). The soil organic matter prediction models based on soil color have simplicity and potential to be used in the laboratory and in the field with quick and unnecessary chemical products, especially for Ultisols and Oxisols of clayey texture.
\end{abstract}

Key words: texture, soil class, soil color, colorimeter. 


\section{INTRODUÇÃO}

Dentre as propriedades do solo, a cor é um atributo com largo espectro de uso, sendo empregada como propriedade diferencial para o nível categórico de Subordem para Latossolos, Argissolos e Nitossolos no Sistema Brasileiro de Classificação de Solos (SiBCS) (Embrapa, 2006). Neste caso, a cor é determinada no campo por comparação visual de amostras secas (nos horizontes superficiais e subsuperficiais) e úmidas (horizontes subsuperficiais) de terra, tendo como padráo a carta de cores de Munsell (Munsell, 1905). Este procedimento traz consigo problemas referentes à subjetividade da interpretaçáo da cor pelo olho humano, efeito causado pelas características da luz incidente sobre o solo, características da superfície do solo e qualidade da resposta do olho humano, uma vez que não são fatores controlados, conforme comprovado por Campos e Demattê (2004).

O surgimento de instrumentos de medida espectral (colorímetros e espectrorradiômetros) permitiu a eliminação das variáveis não controladas, tornando as leituras mais precisas. O colorímetro utiliza um sensor para quantificar a energia refletida na região do espectro visível, resultante da interação da luz com o solo, e por meio de recursos eletrônicos pode convertê-la em diversos sistemas de cor, como, por exemplo, o sistema de cores de Munsell (Munsell, 1905), que foi utilizado neste trabalho. Nesse sistema, a cor é representada em função de três componentes: matiz, valor e croma. $\mathrm{O}$ matiz está relacionado com as cores vermelho, amarelo e da mistura entre ambas, e que segundo EMBRAPA (2006), essa pigmentação está relacionada principalmente aos teores de hematita e goetita do solo. O valor está relacionado com a luminosidade do solo, onde o valor mínimo é a ausência de luminosidade (preto) e o valor máximo a maior luminosidade (branco). O croma representa a intensidade ou pureza da cor em relação ao cinza (MunSELL, 1905).

A cor do solo pode variar de acordo com seus constituintes (Schwertmann, 1993), como óxidos de ferro, matéria orgânica $(\mathrm{MO})$, umidade e granulometria (FerNANDEZ e Schulze, 1992). O teor de MO está diretamente relacionado com a qualidade do solo, atuando em mecanismos que permitem a manutenção da sua capacidade produtiva e sua conservação. Porém, a análise laboratorial do teor de MO no solo é custosa e demanda tempo considerável, além de gerar resíduos químicos que podem causar sérios problemas para os seres humanos e o meio ambiente. Por este motivo, muitos trabalhos científicos utilizando sensores proximais e remotos estão sendo desenvolvidos para auxiliar ou até mesmo substituir a análise convencional de laboratório. Entre as alternativas avaliadas estâo a fotografia aérea (CHEN et al., 2005), a imagem fotográfica (FoX e SABbaGH, 2002; VIsCARRA et al., 2008) e a carta de cores de Munsell (Alexander, 1971; SCHulZE et al., 1993).
Este trabalho teve como objetivo desenvolver modelos matemáticos para quantificar o teor de $\mathrm{MO}$ presente em amostras de solo predominantemente goetíticos em funçáo dos componentes croma e valor da cor do solo no sistema Munsell obtidos por colorímetro. Como hipótese, espera-se que o teor de MO altere a pureza da cor (croma) e intensidade de luz refletida (valor) do solo e que essa relação possa ser modelada matematicamente com razoável acurácia. Tais modelos significariam reduçáo de tempo e custo na estimativa dos teores de $\mathrm{MO}$ em laboratório, assim como eliminação dos resíduos químicos advindos da análise convencional. Conforme observado na literatura, o uso do colorímetro para obtenção da cor do solo correlaciona-se bem com a leitura de cores através da carta de cores de Munsell no campo (Post et al., 1993; ВотеLho et al., 2006), indicando o uso potencial dos modelos para estimar teores de MO de forma rápida e direta no campo.

\section{MATERIAL E MÉTODOS}

A área de estudo compreende aproximadamente 28.000 ha e está localizada nas proximidades do município de Porto Grande, Amapá entre as latitudes $00^{\circ} 00^{\prime}$ e $4^{\circ} 00^{\prime}$ Norte e longitudes $49^{\circ} 30^{\prime}$ e $54^{\circ} 00^{\prime}$ Oeste. A geologia regional é dominada pela formação Barreiras, sendo representada por estruturas mal consolidadas, argilosas, siltosas e arenosas, apresentando por vezes níveis e leitos mais grosseiros, bem como espessos pacotes de caulim. $\mathrm{Na}$ coloração do solo há uma gama de tons (matizes), mas predominam os tons avermelhados, amarelados e esbranquiçados. O clima da região é classificado segundo Köppen como Amw' - tropical chuvoso, com pequena estaçáo seca definida. A temperatura média anual está em torno de $25{ }^{\circ} \mathrm{C}$, com umidade relativa na faixa de $80 \%$ a $85 \%$, precipitação pluvial na faixa de 2.250 a $2.500 \mathrm{~mm}$ e evapotranspiração média anual de $1130 \mathrm{~mm}$, sendo marcante a influência das oscilaçóes da frente intertropical (Projeto Radam, 1974).

Em função da grande extensão da área de estudo, foi estabelecido um grid amostral em toposequência visando minimizar a quantidade de pontos de tradagem mantendo a representatividade da variabilidade química e física dos solos. O planejamento das áreas de tradagem foi feito utilizando-se informaçóes de mapas pré-existentes em nível exploratório (Projeto Radam, 1974) e modelo numérico do terreno (Miranda, 2005). No total, foram estabelecidos 306 pontos amostrais (Figura 1), onde foram coletadas amostras de solo com o auxílio de um trado do tipo holandês nas seguintes profundidades: 0-20, 40-60 e 80-100 cm (quando sem nenhum impedimento físico do solo), totalizando 912 amostras.

As amostras de solo foram enviadas para análise química $(\mathrm{pH}, \mathrm{MO}$, fósforo, potássio, cálcio, magnésio, 


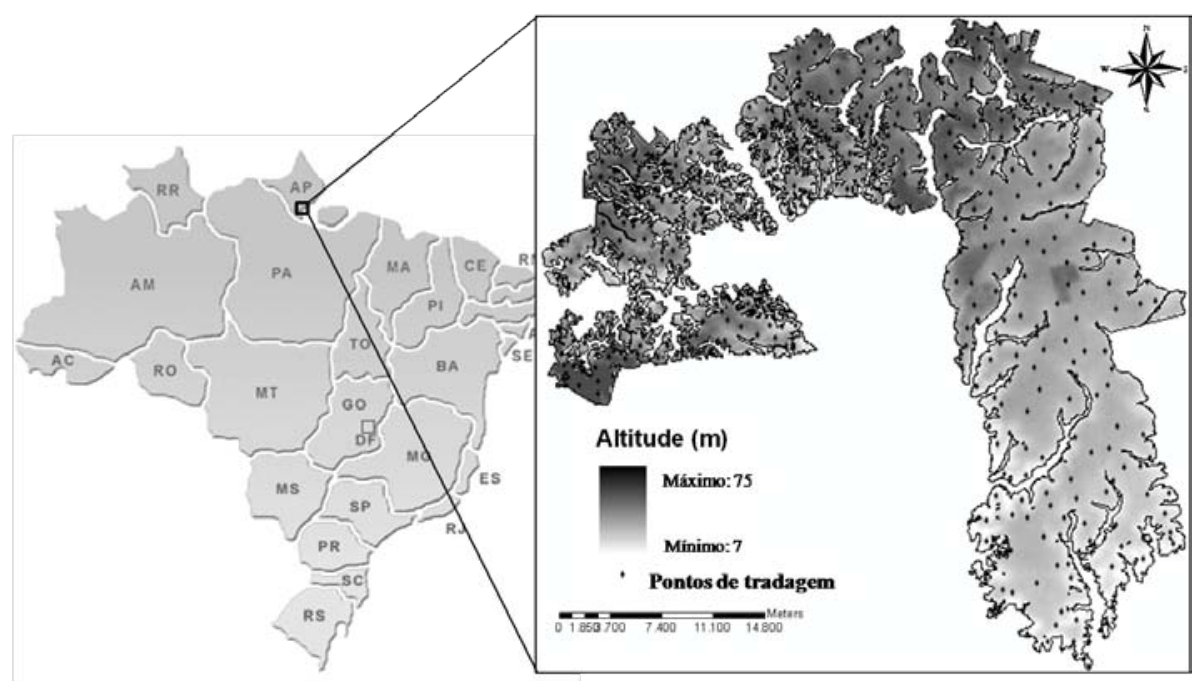

Figura 1. Ilustração do local estudado e dos pontos de tradagem do solo, totalizando 306 pontos para o total aproximado de 28 mil ha.

alumínio, CTC, V\% e m\%) segundo Raij et al. (1987), granulométrica (areia, silte e argila) usando o hidróxido de sódio como dispersante (CAMARgo et al., 1986) e obtenção da cor. Neste último caso, as amostras foram previamente secas (estufa a $45^{\circ} \mathrm{C}$ durante 24 horas), moídas e peneiradas (malha de $2 \mathrm{~mm}$ ). Em seguida, uma camada espessa com $50 \mathrm{~g}$ de amostra foi colocada em placa de petri, recoberta por uma lâmina de quartzo e sua cor obtida no sistema Munsell de cores pelo colorímetro Konica Minolta CR-300 (Konica Minolta Holdings Inc., Tóquio, Japáo) previamente calibrado com placa branca. Para a leitura de cor de solo úmido, borrifou-se a amostra na placa de petri com $50 \mathrm{~mL}$ água antes da leitura.

Somente os componentes, valor e croma foram utilizados para calibrar o modelo de predição de $\mathrm{MO}$, sendo eles: valor de amostra seca (VALS), croma de amostra seca (CRS), valor de amostra úmida (VALU) e croma de amostra úmida (CRU). O matiz foi descartado da análise porque, segundo EMbrapa (2006), sua variação está ligada fundamentalmente aos teores de hematita e goetita do solo, não sendo, portanto de interesse para este trabalho.

Com os resultados químicos, granulométricos e da cor de cada amostra, gerou-se um banco de dados, em que cada ponto amostral foi classificado de acordo com o SiBCS (Embrapa, 2006) até o segundo nível categórico (incluindo caráter textural). Dessa forma, foram identificadas 13 classes de solo: Neossolo Quartzarênico textura muito arenosa (RQ1; 2 perfis), Neossolo Quartzarênico textura arenosa (RQ2; 1 perfil), Neossolo Quartzarênico hidromórfico textura muito arenosa (RQg; 1 perfil), Cambissolo indiscriminado (CX; 2 perfis), Associação de Gleissolos Pouco Húmicos, Alúvicos e Hidromórficos indiscriminados com material plíntico e laterítico (GPH; 2 perfis), Latossolo Amarelo textura argilosa (LA1; 113 perfis), Latossolo Amarelo textura média-argilosa (LA2; 94 perfis), Latossolo Amarelo textura média-arenosa (LA3;
60 perfis), Argissolo Amarelo textura argilosa (PA1; 5 perfis), Argissolo Amarelo textura média-argilosa (PA2; 6 perfis), Argissolo Amarelo textura média-arenosa (PA3; 1 perfil), Associação de solo Petroplíntico, exposiçáo laterítica, Cambissolo, solos Concrecionários e Latossolo cascalhento (PTR; 12 perfis) e Associação de solos Concrecionários, textura indiscriminada com PTR e CX (SC; 7 perfis).

A textura das amostras nas três profundidades foi classificada de acordo com o teor de argila em seis classes texturais (Lemos e SANTos, 1996): 1 - muito argilosa (teor de argila maior do que $610 \mathrm{~g} \mathrm{~kg}^{-1}$ solo); 2 - argilosa (teor de argila entre 360 e $600 \mathrm{~g} \mathrm{~kg}^{-1}$ solo); 3 - médioargilosa (teor de argila entre 260 e $350 \mathrm{~g} \mathrm{~kg}^{-1}$ solo); 4 médio-arenosa (teor de argila entre 160 e $250 \mathrm{~g} \mathrm{~kg}^{-1}$ solo); 5 - arenosa (teor de argila entre 100 e $150 \mathrm{~g} \mathrm{~kg}^{-1}$ solo); e 6 - muito arenosa (teor de argila menor do que $100 \mathrm{~g}$ $\mathrm{kg}^{-1}$ solo).

Modelos de quantificação de $\mathrm{MO}$ em função do valor e croma foram gerados no SPSS (SPSS Inc., Chicago, EUA) através de regressão linear múltipla usando seleção passo a passo (stepwise) ao nível de $95 \%$ de confiança. Por cada classe de solo, o conjunto amostral foi dividido aleatoriamente em um subconjunto para calibraçáo dos modelos, contendo aproximadamente $2 / 3$ dos perfis, e um subconjunto exclusivamente para validação, sendo o conjunto amostral total posteriormente recomposto. Dessa forma, dos 306 perfis de solo (912 amostras), 204 perfis (610 amostras) foram utilizados para desenvolver os modelos e 102 perfis (302 amostras) foram utilizados para validá-los, representando assim a variabilidade de classes e texturas de solo nos dois subconjuntos.

Relaçôes quadráticas foram observadas entre $\mathrm{MO}$ e componentes da cor do solo seco e úmido (Figura 2). Portanto, o quadrado dos valores de componentes de cor $\left(\mathrm{VALS}^{2}, \mathrm{CRS}^{2}, \mathrm{VALU}^{2}\right.$ e CRU ${ }^{2}$ ) foi incluído no banco de dados para desenvolvimento dos modelos. Quando a 
(a)

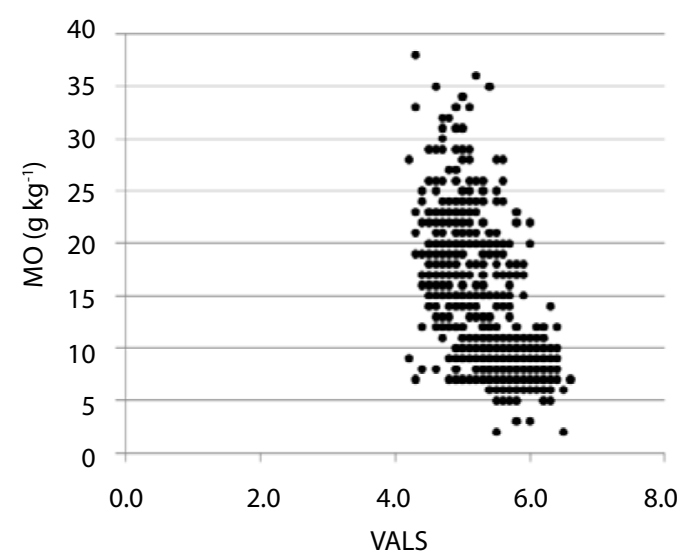

(c)

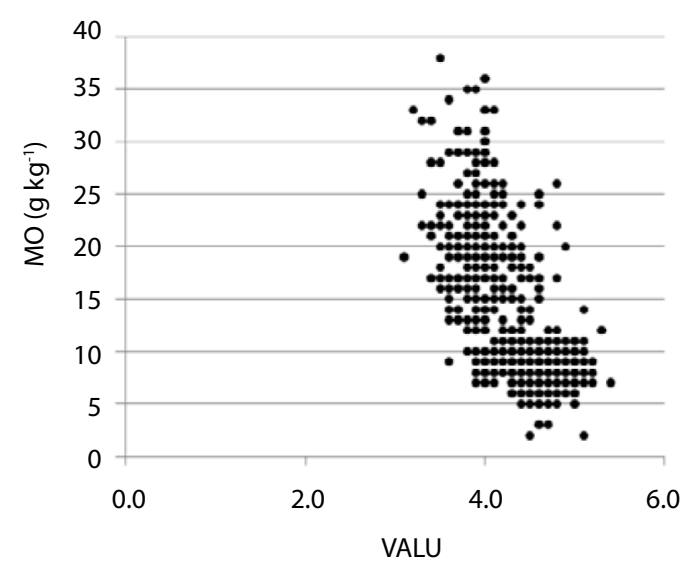

(b)

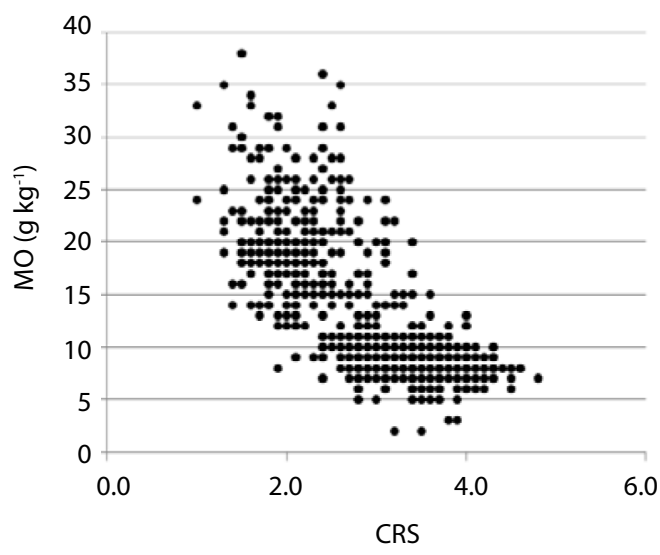

(d)

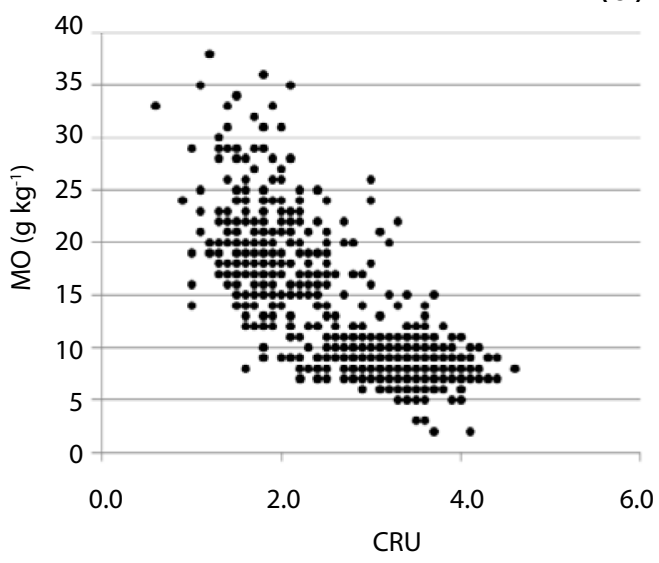

Figura 2. Relação entre teor de matéria orgânica (MO) do solo e componentes da cor do solo, sendo: (a) valor de solo seco (VALS), (b) croma de solo seco (CRS), (c) valor de solo úmido (VALU) e (d) croma de solo úmido (CRU).

relação quadrática foi significativa, o modelo selecionou essas variáveis; caso contrário, somente as variáveis originais foram selecionadas.

Visando aperfeiçoar os modelos de predição de $\mathrm{MO}$, três opçôes de estratificação do conjunto amostral de solos foram testadas, quais sejam: (a) população completa incluindo todas as amostras (modelo único); (b) estratificação por classe de solo; e (c) estratificação por classe textural. Para essa etapa, as 13 classes de solo originais foram agrupadas em cinco conjuntos, sendo: Neossolos $(\mathrm{RQ}=\mathrm{RQ} 1+\mathrm{RQ} 2+\mathrm{RQg})$, Latossolos $(\mathrm{LA}$ $=\mathrm{LA} 1+\mathrm{LA} 2+\mathrm{LA} 3)$, Argissolos $(\mathrm{PA}=\mathrm{PA} 1+\mathrm{PA} 2+$ $\mathrm{PA} 3)$, Gleissolos (GPH) e solos com evidência de material de origem $(S R M=C X+P T R+S C)$. Outliers de influência no ajuste de alguns modelos foram identificados e removidos quando a distância de Cook da amostra foi superior ao valor de $F$ tabelado ao nível de $50 \%$ de confiança com $p, n-p$ graus de libertade, onde $p$ é o número de variáveis independentes e $n$ o número de amostras utilizadas no modelo (Cook, 1977). Além do teste de outliers, todos os pressupostos da regressáo linear múltipla foram testados e atendidos por todos os modelos gerados.

\section{RESULTADOS E DISCUSSÃO}

Por meio da análise da estatística descritiva para os dados de MO determinados em laboratório (Tabela 1), observase uma grande variação entre os valores mínimo e máximo, concordando com observaçôes de autores como VISCARra Rossel et al. (2008) e Walter et al. (1997).

Os coeficientes de correlação $(r)$ entre $\mathrm{MO}$ e os componentes valor e croma (Tabela 1), tanto para amostras secas quanto úmidas, mostram que estes estão diretamente relacionados, corroborando o resultado verificado por Fontes e Carvalho Junior. (2005) para solos também predominantemente goetíticos. Todos os valores de $r$ são negativos, indicando que para valores crescentes de valor e croma o teor de MO diminui. Esse padrão pode ser confirmado visualmente na carta de cores de Munsell, cujos valores mais elevados de valor e croma em solos de cores mais claras correspondem geralmente a menores teores de MO.

Os modelos de quantificação de $\mathrm{MO}$ para as três estratificaçôes propostas representam sistematicamente maior $\mathrm{R}^{2}$ com base em cores de amostras úmidas em relação a amostras secas (Tabelas 2 e 3). Resultados semelhantes 
Tabela 1. Estatística descritiva da matéria orgânica (MO) e componentes da cor do solo seco (valor - VALS; croma - CRS) e úmido (valor - VALU; croma - CRU)

\begin{tabular}{|c|c|c|c|c|c|}
\hline \multirow{2}{*}{ Estatística } & MO & VALS & CRS & VALU & CRU \\
\hline & \multicolumn{5}{|c|}{$\mathrm{g} \mathrm{kg}^{-1}$} \\
\hline Média & 12,39 & 5,42 & 2,99 & 4,37 & 2,85 \\
\hline Erro-padrão da média & 0,21 & 0,02 & 0,02 & 0,01 & 0,03 \\
\hline Mínimo & 2 & 4,20 & 1,00 & 3,10 & 0,60 \\
\hline Máximo & 38 & 6,60 & 4,80 & 5,40 & 4,60 \\
\hline Mediana & 9,50 & 5,50 & 3,20 & 4,40 & 3,10 \\
\hline Desvio-padrão & 6,39 & 0,49 & 0,75 & 0,41 & 0,83 \\
\hline Assimetria (skewness) & 1,28 & $-0,18$ & $-0,41$ & $-0,31$ & $-0,46$ \\
\hline Correlação com MO & 1,00 & $-0,60$ & $-0,76$ & $-0,70$ & $-0,79$ \\
\hline
\end{tabular}

Tabela 2. Resultados da regressão linear múltipla da matéria orgânica (MO) do solo em função dos componentes valor (VALS) e croma (CRS) da cor do solo seco

\begin{tabular}{|c|c|c|c|c|c|}
\hline \multirow{3}{*}{ Dados* } & \multicolumn{2}{|c|}{ Calibração } & \multicolumn{2}{|c|}{ Validação } & \multirow{2}{*}{ Modelo } \\
\hline & $\mathbf{N}$ & $\mathbf{R}^{2}$ & $\mathbf{N}$ & $\mathbf{R}^{2}$ & \\
\hline & \multicolumn{5}{|c|}{ Sem estratificação } \\
\hline \multirow[t]{2}{*}{ Todas as amostras } & 610 & 0,62 & 302 & 0,56 & $\mathrm{MO}=44,62-16,25^{*} \mathrm{CRS}+1,73^{*} \mathrm{CRS}^{2}$ \\
\hline & \multicolumn{5}{|c|}{ Estratificação por classe de solo } \\
\hline LA & 537 & 0,64 & 261 & 0,63 & $\mathrm{MO}=47,23-17,97^{*} \mathrm{CRS}+2,00^{*} \mathrm{CRS}^{2}$ \\
\hline PA & 24 & 0,77 & 12 & 0,63 & $\mathrm{MO}=38,22-13,78^{*} \mathrm{CRS}+1,51^{*} \mathrm{CRS}^{2}$ \\
\hline SRM & 37 & 0,50 & 22 & 0,25 & $\mathrm{MO}=27,77-1,65^{*} \mathrm{CRS}^{2}$ \\
\hline $\mathrm{RQ}^{* *}$ & 9 & & 3 & & \\
\hline \multirow[t]{2}{*}{$\mathrm{GPH}^{* *}$} & 3 & & 3 & & \\
\hline & \multicolumn{5}{|c|}{ Estratificação por classe de textura } \\
\hline Muito argilosa & 41 & 0,56 & 13 & 0,38 & $\mathrm{MO}=83,69-44,17^{*} \mathrm{CRS}+6,51^{*} \mathrm{CRS}^{2}$ \\
\hline Argilosa & 194 & 0,67 & 105 & 0,59 & $\mathrm{MO}=56,58-22,93^{*} \mathrm{CRS}+2,64^{*} \mathrm{CRS}^{2}$ \\
\hline Médio-argilosa & 198 & 0,64 & 105 & 0,60 & $\mathrm{MO}=44,09-16,35^{*} \mathrm{CRS}+1,80^{*} \mathrm{CRS}^{2}$ \\
\hline Médio-arenosa & 152 & 0,61 & 71 & 0,58 & $\mathrm{MO}=29,79-5,83^{*} \mathrm{CRS}$ \\
\hline Arenosa & 16 & 0,74 & 4 & 0,04 & $\mathrm{MO}=22,70-1,16^{*} \mathrm{CRS}^{2}$ \\
\hline Muito arenosa & 7 & 0,93 & 1 & & $\mathrm{MO}=45,43-15,91{ }^{*} \mathrm{CRS}$ \\
\hline
\end{tabular}

foram observados por Wills et al. (2007) e Viscarra Rossel et al. (2008) para mediçóes de carbono orgânico do solo. Quando o solo é umedecido, ocorre uma alteração na percepçáo de sua cor, devido à maior absorçấo de energia luminosa pelas moléculas de água (KIEHL, 1979; Demattê et al., 2006), tendo como efeito a homogeneização da cor do solo (VISCARRa Rossel et al., 2008). Tal padrão resulta em melhores modelos de predição de $\mathrm{MO}$ do solo. Por esse motivo, os resultados com base em cores de amostras úmidas foram usados como referência para discussão dos modelos gerados para as três estratificações propostas. Para fins comparativos, a tabela 2 resume os resultados obtidos usando cores de amostras secas.

A primeira estratificação, que envolve a população completa (Tabela 3), resultou em $\mathrm{R}^{2}$ de 0,66 tanto para ca- libração quanto validação do modelo. Tanto o valor como o croma foram significativos e utilizados no modelo. A utilizaçáo de ambos os componentes de cor para predizer MO do solo de forma mais acurada já foi observada em outros trabalhos; por exemplo, Blume e Helsper (1987), Franzmeier (1993) e Wills et al. (2007) obtiveram R ${ }^{2}$ em torno de 0,65 estimando carbono orgânico em solos agrícolas. Fox e SABBAGH (2002) estimaram o teor de matéria orgânica do solo utilizando as bandas de vermelho, verde e azul de fotografias aéreas, obtendo $\mathrm{R}^{2} \mathrm{em}$ torno de 0,70. Em contrapartida, Schulze et al. (1993) não conseguiram produzir bons modelos de predição de MO. Segundo os autores, essa limitação foi decorrente da grande variabilidade de textura dos solos que compunham o conjunto de amostras analisado. Nos modelos estratificados 
Tabela 3. Resultados da regressão linear múltipla da matéria orgânica (MO) do solo em função dos componentes valor (VALU) e croma (CRU) da cor do solo úmido

\begin{tabular}{|c|c|c|c|c|c|}
\hline \multirow{3}{*}{ Dados* $^{*}$} & \multicolumn{2}{|c|}{ Calibração } & \multicolumn{2}{|c|}{ Validação } & \multirow{2}{*}{ Modelo } \\
\hline & $\mathbf{N}$ & $\mathbf{R}^{2}$ & $\mathbf{N}$ & $\mathbf{R}^{2}$ & \\
\hline & \multicolumn{5}{|c|}{ Sem estratificação } \\
\hline \multirow[t]{2}{*}{ Todas as amostras } & 610 & 0,66 & 302 & 0,66 & $\begin{aligned} \mathrm{MO}= & 93,95-12,09^{*} \mathrm{CRU}+1,30^{*} \mathrm{CRU}^{2}- \\
& 25,09^{*} \mathrm{VALU}+2,66^{*} \mathrm{VALU}^{2}\end{aligned}$ \\
\hline & \multicolumn{5}{|c|}{ Estratificação por classe de solo } \\
\hline LA & 537 & 0,69 & 261 & 0,73 & $\begin{aligned} \mathrm{MO}= & 91,18-12,87^{*} \mathrm{CRU}+1,44^{*} \mathrm{CRU}^{2}- \\
& 22,92^{*} \mathrm{VALU}+2,37^{*} \mathrm{VALU}^{2}\end{aligned}$ \\
\hline PA & 24 & 0,85 & 12 & 0,73 & $\mathrm{MO}=35,38-12,22^{*} \mathrm{CRU}+1,32^{*} \mathrm{CRU}^{2}$ \\
\hline SRM & 37 & 0,42 & 22 & 0,21 & $\mathrm{MO}=29,71-6,34^{*} \mathrm{CRU}$ \\
\hline $\mathrm{RQ}^{* *}$ & 9 & & 3 & & \\
\hline \multirow[t]{2}{*}{$\mathrm{GPH}^{* *}$} & 3 & & 3 & & \\
\hline & \multicolumn{5}{|c|}{ Estratificação por classe de textura } \\
\hline Muito argilosa & 41 & 0,74 & 13 & 0,81 & $\mathrm{MO}=67,63-31,04^{*} \mathrm{CRU}+4,07^{*} \mathrm{CRU}^{2}$ \\
\hline Argilosa & 194 & 0,69 & 105 & 0,72 & $\mathrm{MO}=48,20-18,92^{*} \mathrm{CRU}+2,18^{*} \mathrm{CRU}^{2}$ \\
\hline Médio-argilosa & 198 & 0,70 & 105 & 0,69 & $\begin{aligned} \mathrm{MO}= & 123,55-12,13^{*} \mathrm{CRU}+1,41^{*} \mathrm{CRU}^{2}- \\
& 38,08^{*} \mathrm{VALU}+4,02 * \mathrm{VALU}^{2}\end{aligned}$ \\
\hline Médio-arenosa & 152 & 0,66 & 71 & 0,65 & $\mathrm{MO}=37,69-13,85^{*} \mathrm{CRU}+1,55^{*} \mathrm{CRU}^{2}$ \\
\hline Arenosa & 16 & 0,88 & 6 & 0,13 & $\mathrm{MO}=22,17-1,32^{*} \mathrm{CRU}^{2}$ \\
\hline Muito arenosa & 7 & 0,86 & 1 & & $\mathrm{MO}=75,01-15,48^{*}$ VALU \\
\hline
\end{tabular}

por classe de solo ou classe de textura, a inclusão de ambos os componentes de cor não é uma constante. Nesse caso, o croma é utilizado na maioria dos modelos. Vale ressaltar que a relação quadrática entre os componentes de cor e MO foi confirmada na maioria dos modelos, sendo significativa ao nível de $95 \%$ de confiança.

Dentre os resultados referentes às classes de solo, apenas nos Argissolos e Latossolos houve modelos expressivos (Tabela 3), que, quando validados com amostras independentes, apresentaram $\mathrm{R}^{2}$ de 0,73 e 0,72 respectivamente. Os Argissolos comumente possuem transição clara entre horizontes $\mathrm{A}$ e $\mathrm{B}$, ou seja, o decréscimo de $\mathrm{MO}$ em profundidade é acompanhado intimamente pela variação de cor. Essa relação direta entre os componentes de cor e $\mathrm{MO}$, quando utilizada para a predição de modelos matemáticos, permitiu melhor acurácia dos resultados. Em grande parte dos Latossolos, ocorre transição difusa entre horizontes subsuperficiais, o que demonstra que a reduçáo de $\mathrm{MO}$ em profundidade causa pouca ou nenhuma alteração na cor do solo. Esse mascaramento resultou em menor valor de $\mathrm{R}^{2}$ no modelo de calibração dos Latossolos $(0,69)$, quando comparado com o resultado dos Argisso$\operatorname{los}\left(\mathrm{R}^{2}=0,85\right)$.

No caso das classes de solo agrupadas como SRM, o modelo para quantificaçáo de MO foi inexpressivo, com $\mathrm{R}^{2}$ de 0,43 (Tabela 3). Neste caso, pode-se atribuir o resultado à presença marcante de minerais primários de cores variadas no solo. A maior expressão destes deve-se ao intemperismo relativamente limitado do material de origem, o que pode mascarar a cor derivada do teor de $\mathrm{MO}$ em meio à variedade de cores dos diferentes minerais. Outra fonte de mascaramento dos pigmentos da $\mathrm{MO}$ é a presença de concreçôes em solos (concrecionários) no grupo dos SRM, as quais possuem diferentes coloraçóes devido à presença de ferro em diferentes formas e estágios de intemperização. Quando moídas, essas concreções formam um material de pigmentos muito heterogêneos que, quando misturado à massa de solo, pode diminuir a interação entre valor e croma gerais do solo e o teor de MO.

Com relação à textura, os resultados indicam tendência de melhoria dos valores de $\mathrm{R}^{2}$ com o aumento de argila no solo (Tabela 3). Esse fato pode ser explicado quando analisada a influência da granulometria do solo na sua pigmentação, ou seja, na expressão da sua cor, que está diretamente ligada à superfície específica dos materiais que compóem os solos (Oliveira, 2005). Demattê et al. (2003) verificaram que pequenas alteraçóes de pigmentação são mais expressivas na intensidade de reflectância de solos arenosos do que argilosos, efeito comumente visto no campo. Tais autores observaram, por exemplo, que Neossolos Quartzarênicos contendo apenas $20 \mathrm{~g} \mathrm{~kg}^{-1}$ de $\mathrm{Fe}_{2} \mathrm{O}_{3}$ têm cor semelhante (3YR 3/4) à dos Latossolos Vermelhos. Ainda devido a esse padrão, AleXAnder (1971) observou que amostras de terra de textura mais arenosa tiveram o teor de $\mathrm{MO}$ superestimado em funçâo da sua cor. Esses resultados demonstram que, solos com tendência 
a granolumetrias mais grosseiras, pequenas variaçóes de MO podem refletir em grande variação da cor resultante do solo. Essa sensibilidade à pigmentação das fraçôes mais grosseiras do solo, decorrente de sua menor superfície específica, influenciou nos resultados referentes às classes de textura mais arenosas, em que maior variabilidade de tons de valor e croma, associada à menor correlação entre $\mathrm{MO}$ e cor, resultaram em menores valores de $\mathrm{R}^{2}$ quando comparados às classes de textura mais argilosas.

Ressaltamos que os modelos gerados consideram duas propriedades que refletem a variação de $\mathrm{MO}$ no solo: os componentes valor e croma. Essas propriedades da cor do solo, em geral, são avaliadas em conjunto. Porém, conforme observamos nos modelos de predição de amostras úmidas (Tabela 3), não há necessidade de avaliar ambos os componentes da cor dependendo da textura ou classe de solo. Para amostras secas (Tabela 2), esse fato é mais evidente, já que nenhum dos modelos incluiu o componente valor, mostrando que se tornou redundante após a inclusão do croma nos modelos. Tal fato sugere que a influência da MO na cor do solo ocorre primordialmente através da pigmentação do solo, fornecendo-lhe cores mais vivas (maior croma), e secundariamente e somente em alguns casos, através do escurecimento do solo (diminuição do valor).

\section{CONCLUSÃO}

É possível estimar o teor de matéria orgânica com um $\mathrm{R}^{2}$ de 0,66 em amostras úmidas predominantemente goetíticas, utilizando-se os valores de valor e croma obtidos por colorímetro.

Os valores dos componentes valor e croma são inversamente proporcionais ao teor de matéria orgânica. O componente valor isoladamente não é adequado para prediçấo do teor de matéria orgânica no solo. No entanto, em conjunto com o croma, complementa o modelo de predição aumentando ligeiramente $\mathrm{o} \mathrm{R}^{2}$.

Em alguns casos é possível melhorar a correlação entre matéria orgânica e cor do solo classificando-se a amostra por classe de solo ou textura. Para classes de solo, essa correlação se aplica somente aos Latossolos e aos Argissolos, podendo chegar a valores de validação $\mathrm{R}^{2}$ de 0,73 e 0,72 respectivamente. Para classes texturais, aplica-se somente a solos com teor de argila acima de $250 \mathrm{~g} \mathrm{~kg}^{-1}$ solo (classes 1 a 3) com amostras úmidas. O teor de matéria orgânica no solo, em geral, possui melhor correlação com a cor do solo em amostras úmidas do que secas.

\section{AGRADECIMENTOS}

$\mathrm{O}$ primeiro e segundo autores agradecem ao $\mathrm{CNPq}$ pelas bolsas concedidas, respectivamente, de pequisa (CNPq/
PQ e CNPq/PIBIC (111476/2004-2006) pelo apoio financeiro para realizaçáo deste experimento e pela bolsa pesquisador.

\section{REFERÊNCIAS}

ALEXANDER, J.D. Color chart for estimating organic carbon in mineral soils in Illinois. Champaign: University of Illinois, Cooperative Extension Service, 1971. (University of Illinois Cooperative Extension Service Bulletin, AG-1941)

BLUME, H.-P.; HELSPER, M. Schãtzung des humusgehaltes nach dr Munsell-farbhellighkeit. Zeitschrift für Pflanzenernährung und Bodenkunde, v.150, p.354-356, 1987.

BOTELHO, M.R.; DALMOLIN, R.S.D.; PEDRON, F.A; AZEVEDO, A.C.; RODRIGUES, R.B.; MIGUEL, P. Medida da cor em solos do Rio Grande do Sul com a carta de Munsell e por colorimetria. Ciência Rural, v.36, p.1179-1185, 2006.

CAMARGO, A.O.; MONIZ, A.C.; JORGE, J.A.; VALADARES, J.M. Métodos de análise química, mineralógica e física de solos do IAC. Campinas: IAC, 1986. 77p. (Boletim Técnico, 106)

CAMPOS, R.C.; DEMATTÊ, J.A.M. Cor do solo: uma abordagem da forma convencional de obtençấo em oposição à automatização do método para fins de classificação de solos. Revista Brasileira de Ciência do Solo, v.28, p.853-863, 2004.

DEMATTÊ, J.A.M.; EPHIPHANIO, J.C.N.; FORMAGGIO, A.R. Influência da matéria orgânica e de formas de ferro na reflectância de solos tropicais. Bragantia, v.62, p.451-464, 2003.

DEMATTÊ, J.A.M.; SOUSA, A.A.; ALVES, M.C.; NANNI, M.R.; FIORIO, P.R.; CAMPOS, R.C. Determining soil water status and other soil characteristics by spectral proximal sensing. Geoderma, v.135, p.179-195, 2006.

CHEN, F.; KISSEL, D.E.; WEST, L.T.; RICKMAN, D.; LUVALL, J.C.; ADKINS, W. Mapping surface soil organic carbon for crop fields with remote sensing. Journal of Soil Water Conservation, v.61, p.51-57, 2005.

COOK, R.D. Detection of influential observation in linear regression. Technometrics, v.19, p.15-18, 1977.

EMBRAPA (EMPRESA BRASILEIRA DE PESQUISA AGROPECUÁRIA). CENTRO NACIONAL DE PESQUISA DE SOLOS. Sistema brasileiro de classificação de solos. 2.ed. Rio de Janeiro: Embrapa Solos, 2006. 306p.

FERNANDEZ, R.N.; SCHULZE, D.G. Munsell colors of soils simulated by mixtures of goethite and hematite with kaolinite. Zeitschrift für Pflanzenernährung und Bodenkunde, v.155, p.473478, 1992.

FRANZMEIER, D.P. Relation of organic matter content to color of Indiana soils. Indiana Academic Science Proceedings, v.98, 156168, 1993.

FONTES, M.P.F.; CARVALHO JUNIOR, I.A. Color attributes and mineralogical characteristics, evaluated by radiometry, of highly 
weathered tropical soil. Soil Science Society of America Journal, v.69, p.1162-1172, 2005.

FOX, G.A.; SABBAGH, G.J. Estimation of soil organic matter from red and near-infrared remotely sensed data using a soil line Euclidean distance technique. Soil Science Society of America Journal, v.66, p.1922-1929, 2002.

KIEHL, E.J. Manual de edafologia: relaçóes solo-planta. Sáo Paulo: Agronômica Ceres, 1979. 264p.

LEMOS, R.C.; SANTOS, R.D. Manual de descrição e coleta de solo no campo. 3.ed. Campinas: Sociedade Brasileira de Ciência do Solo, 1996. 83p.

MIRANDA, E.E. (Coord.). Brasil em relevo. Campinas: Embrapa Monitoramento por Satélite, 2005. Disponível em: <http://www. relevobr.cnpm.embrapa.br>. Acesso em: 26 abr. 2010.

MUNSELL, A.H. A color notation. Boston: G. H. Ellis, 1905. 90p.

OLIVEIRA, J.B. Pedologia aplicada. Piracicaba: FEALQ, 2005. 574p.

POST, D.F.; LEVINE, S.J.; BRYANT, R.B.; MAYS, M.D.; BATCHILY, A.K.; ESCADAFAL, R.; HUETE, E.A. Correlations between field and laboratory measurements of soil color. In: BIGHAM, J.M.; CIOLKOSZ, E.J. (Ed.). Soil color. Madison: Soil Science Society of America, 1993. p.35-49. (Special Publication, 31)
PROJETO RADAM. Levantamento de recursos naturais. Folha NA/NB.22 - Macapá, v.6, 1974.

RAIJ, B. van.; QUAGGIO, J.A.; CANTARELLA, H.; FERREIRA, M.E.; LOPES, A.S.; BATAGLIA, C.O. Análise química do solo para fins de fertilidade. Campinas: Fundação Cargill, 1987. 170p.

SAS (Statistical Analysis System) Institute Inc. SAS 8.2 user's guide. Cary: SAS Institute Inc., 1999.

SCHULZE, D.G.; NAGEL, J.L.; SCOYOC, G.E.; HENDERSON, T.L.; BAUMGARDNER, M.F.; STOTT, D.E. Significance of organic matter in determining soils colors. In: BIGHAM, J.M.; CIOLKOSZ, E.J. (Ed.). Soil color. Madison: Soil Science Society of America, 1993. p.71-90. (Special Publication, 31)

SCHWERTMANN, U. Relations between iron oxides, soil color, and soil formation. In: BIGHAM, J.M.; CIOLKOSZ, E.J. (Ed.). Soil color. Madison: Soil Science Society of America, 1993. p.5170. (Special Publication, 31)

VISCARRA ROSSEL, R.A.; FOUAD, Y.; WALTER, C. Using a digital camera to measure soil organic carbon and iron contents. Biosystems Engineering, v.100, p.149-159, 2008.

WALTER, C.; SCHVARTZ, C.; CLAUDOT, B.; BOUEDO, T.; AUROUSSEAU, P. Synthèse nationale des analyses de terre réalisées, entre 1990 et 1994. Etude et Gestion des Sols, v.4, p.205-220, 1997.

WILLS, S.A.; BURRAS, C.L.; SANDOR, J.A. Prediction of soil carbon content using field and laboratory measurements of soil color. Soil Science Society of America Journal, v.71, p.380-388, 2007. 